\title{
Dificuldade de aprendizagem do cálculo de área de figuras planas retangulares: uma possibilidade através do GeoGebra
}

\author{
Margaret Charnei \\ UNESPAR - Universidade Estadual do Paraná Campus de Campo Mourão - PR \\ Brasil \\ margaretcharnei@gmail.com
}

\begin{abstract}
This work aims to provide the learning of the area calculation of rectangular flat figures, through a scenario for investigation, making the student protagonist of the process. After analyzing the results of the Prova Parana diagnostic evaluation, applied in two editions in 2019, it was found that urgent changes in the teaching of mathematics are necessary. From the results of Descriptor 13 (solve problems involving the calculation of areas of flat figures), in which the students presented very poor performance. These results were then compared to those verified after the development of activities of this descriptor by the same students in a free math software: GeoGebra.
\end{abstract}

Resumo. Este trabalho tem como objetivo propiciar o aprendizado do cálculo de área de figuras planas retangulares, por meio de um cenário para investigação, tornando o aluno protagonista do processo. Após análise dos resultados da avaliação diagnóstica Prova Paraná, aplicada em duas edições no ano 2019, constatou-se que são necessárias mudanças urgentes no ensino da matemática. A partir dos resultados do Descritor 13 (resolver problemas envolvendo o cálculo de áreas de figuras planas), no qual os alunos apresentaram desempenho muito baixo. Estes resultados foram então comparados àqueles verificados após o desenvolvimento de atividades deste descritor pelos mesmos alunos em um software de matemática gratuito: o GeoGebra.

\section{Introdução}

Atualmente existem na rede pública de ensino do Paraná três sistemas de avaliação externa, apresentados a seguir:

SAEB - Desde 1990, quando foi criado, o SAEB teve algumas reestruturações. Em 2005, passou a ser composto por duas avaliações: a Avaliação Nacional da Educação Básica (Aneb), que manteve as características, os objetivos e os procedimentos da avaliação efetuada até aquele momento; e a Avaliação Nacional do Rendimento Escolar (Anresc), conhecida como Prova Brasil, criada com o objetivo de avaliar a qualidade do ensino ministrado nas escolas das redes públicas. Em 2013, a Avaliação Nacional da Alfabetização (ANA) foi incorporada ao SAEB para melhor aferir os níveis de alfabetização e letramento em Língua Portuguesa (leitura e escrita) e Matemática. Em 2019, as siglas ANA, Aneb e Anresc deixaram de existir e todas as avaliações passaram a ser identificadas pelo nome SAEB, acompanhado das etapas, áreas de conhecimento e tipos de instrumentos envolvidos. As aplicações se 
VIII Congresso Brasileiro de Informática na Educação (CBIE 2019)

Anais dos Workshops do VIII Congresso Brasileiro de Informática na Educação (WCBIE 2019)

concentraram nos anos ímpares e a divulgação dos resultados, nos anos pares e são avaliados os estudantes de creche e educação infantil, dos $5^{\circ}$ e $9^{\circ}$ anos do ensino fundamental e $3^{\circ}$ ano do ensino médio (portal INEP).

SAEP - Criado em 2012, é um sistema próprio de avaliação do Estado do Paraná e tem como objetivo disponibilizar informações relevantes quanto ao desenvolvimento cognitivo dos estudantes, descrevendo os conhecimentos desenvolvidos em Língua Portuguesa e Matemática. A prova é aplicada para os estudantes de $6^{\circ}$ e $9^{\circ}$ anos do ensino fundamental e $1^{\circ}$ e $3^{\circ}$ anos do ensino médio. Foi aplicada nos anos de 2012, 2013, 2017 e 2018.

PROVA PARANÁ - criada em 2019, descrevendo os conhecimentos desenvolvidos em Língua Portuguesa e Matemática. Teve duas edições no primeiro semestre: na $1^{\mathrm{a}}$ edição a prova foi aplicada aos estudantes dos $5^{\circ}, 6^{\circ}$ e $9^{\circ}$ anos do ensino fundamental e $1^{\circ}$ e $3^{\circ}$ anos do ensino médio. Na segunda edição a prova foi aplicada aos estudantes desde o $5^{\circ}$ ano do ensino fundamental até o $3^{\circ}$ ano do ensino médio.

A situação, revelada pelas avaliações anteriormente comentadas, em matemática, é bastante preocupante (figuras 1 e 2):

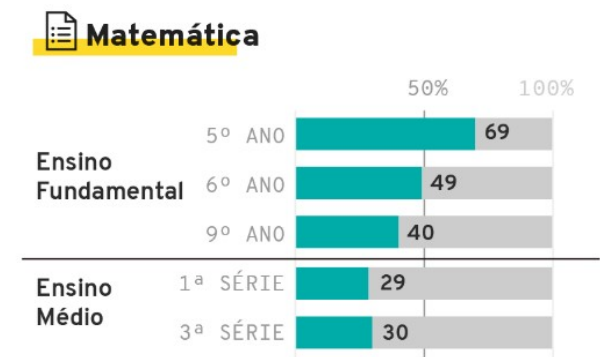

Figura 1. Percentual de acertos para cada ano dos estudantes na $1^{\mathrm{a}}$ edição Prova Paraná

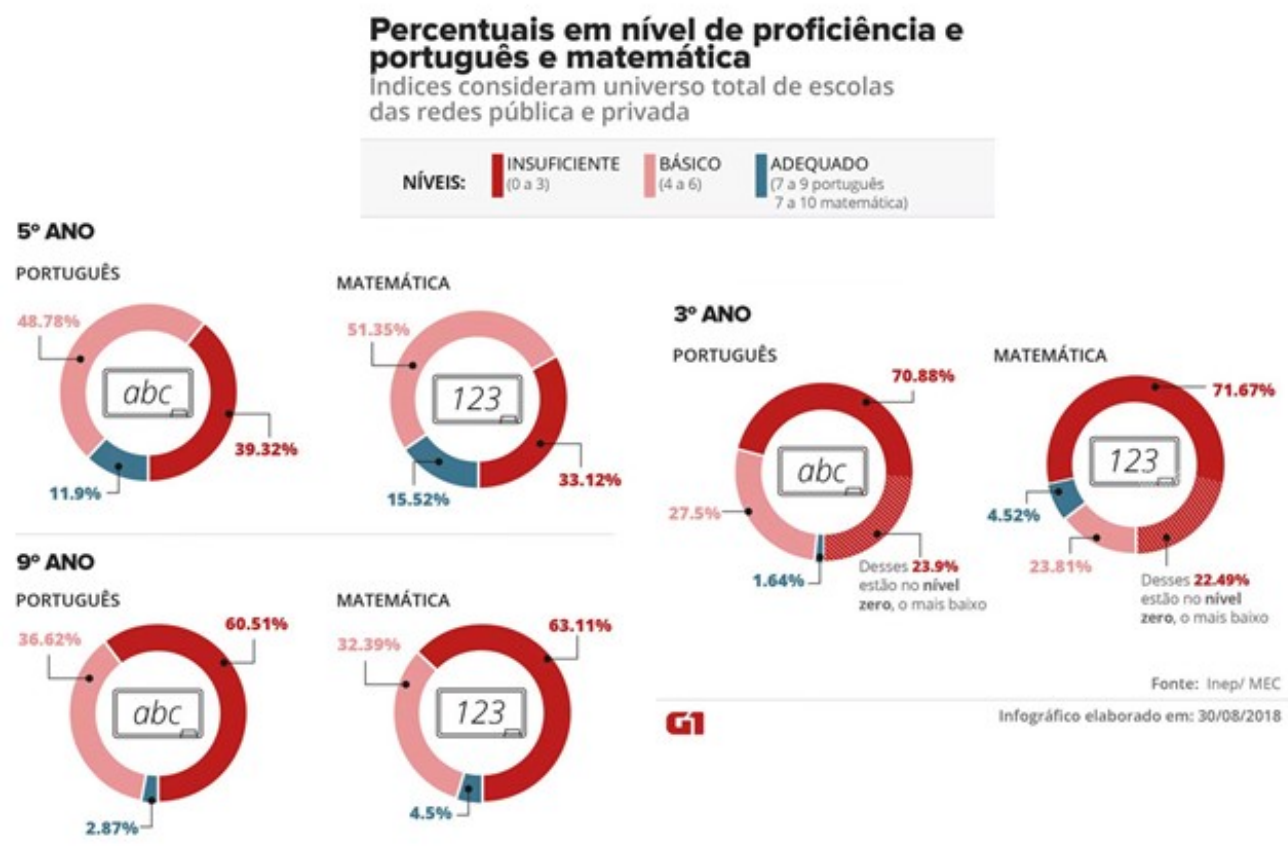

Figura 2: Dados do SAEB 2017 mostram médias de proficiência em português e matemática 
As avaliações externas mostram-se úteis aos professores e a todos os envolvidos no ambiente escolar para apontar elementos que contribuam para o fortalecimento do trabalho docente e da aprendizagem por meio de diagnósticos específicos e, considerando a proficiência dos alunos em relação ao período escolar. Conforme explicam Alavarse; Blasis e Falsarella (2013, p. 12), existe a possibilidade de as avaliações externas fornecerem "pistas importantes para que se reflita sobre o desenvolvimento do trabalho educativo no interior das escolas, especialmente [...] [tratando-se do] conjunto das atividades escolares".

Diante desse cenário, o professor deverá buscar caminhos para situar-se e compreender o contexto em que vive, na comunidade e na escola, procurando resolver os impasses que lhe são peculiares e continuamente presentes em sua sala de aula. Alguns desses impasses fogem do controle do professor, como por exemplo, os problemas sociais, culturais e econômicos que os alunos trazem consigo. Mas o professor precisa refletir sobre o que faz e para que faz, em sala de aula, para assim inserir mudanças no ensino da matemática que, por sua vez, influenciarão no aprendizado e consequentemente nos resultados negativos observados nas avaliações externas.

Uma das mudanças que o professor poderá fazer, que a princípio parece ser uma tarefa desafiadora, é pensar em trabalhar com tecnologias nas aulas de Matemática, recurso muitas vezes não utilizado pela falta de capacitação e pela falta de infraestrutura das escolas. Mas, na realidade, é uma mudança de hábitos na forma de ensinoaprendizagem, cujos resultados podem ser eficientes.

Um dos descritores específicos da matemática que tem chamado a atenção pelo baixíssimo desempenho dos estudantes na Prova Paraná é o Descritor 13 (resolução de problemas envolvendo o cálculo de área de figuras planas). Apesar deste descritor fazer parte do conteúdo estruturante Geometrias, e ter várias das representações de seus objetos na vida real prevalece o paradigma do exercício (Skoysmose, 2000), quando se trabalha esse assunto em sala de aula. Esse paradigma, para Skovsmose (2000), caracteriza aquele encontro em que o professor apresenta algumas ideias e técnicas matemáticas, umas questões são resolvidas e, posteriormente, os alunos resolvem exercícios similares. Nesta abordagem, pode ser dedicado um tempo maior à exposição do professor ou para as resoluções.

Segundo Bernarda Menezes (2018) estes resultados talvez revelem que aí exista um problema quanto ao ensino-aprendizagem de Geometria. Considerando que este é um tópico da Matemática tão manuseável, com tantas aplicações práticas; mas que frequentemente tem sido trabalhado de forma tecnicista.

Em Geometria, os softwares que possibilitam movimentar as figuras e as manipular, facilitam a transição de uma experimentação para um pensamento abstrato. Ou seja, podem facilitar a compreensão conceitual dos objetos, de forma que não precise da interação com os mesmos na construção de um conhecimento futuro.

Borba e Villarreal (2005) apontam a experimentação na Educação Matemática como uma abordagem em harmonia com tecnologias, propondo, então, a abordagem experimental-com-tecnologia (p. 63). E que, quando há tecnologias disponíveis, há também: a possibilidade de testar uma conjectura usando um grande número de exemplos e a chance de repetir os experimentos, devido ao rápido feedback dado pelos computadores; a chance de obter diferentes tipos de representações de uma dada 
VIII Congresso Brasileiro de Informática na Educação (CBIE 2019)

Anais dos Workshops do VIII Congresso Brasileiro de Informática na Educação (WCBIE 2019)

situação de forma mais fácil; uma forma de aprender matemática que é ressonante com modelagem como uma abordagem pedagógica (BORBA e VILLARREAL, 2005, p. 75).

Uma das ferramentas disponíveis para fins didáticos em Geometria é o GeoGebra. Criado em 2001 por Markus Hohenwarter na universidade de Salzburgo (Áustria). O GeoGebra é um ambiente de geometria dinâmica que integra Geometria, Álgebra e Estatística. Com este programa, os alunos podem explorar, testar, aplicar, apagar, fazer de novo, tentar e chegar as suas próprias conclusões, sendo assim protagonistas do aprendizado.

\begin{abstract}
Possui interface amigável, que permite construir de forma precisa e com pouco esforço, modelos que exigiriam grande habilidade se desenhados na lousa. Além da precisão e da beleza, as construções realizadas no GeoGebra obedecem a relações matemáticas que as disciplinam, possibilitando a transformação do visual da página e apresentando dinamismo, que, muitas vezes, convence mais do que qualquer demonstração de resultados (DANTE, 2018, p. 31).
\end{abstract}

Baseado nisso, este trabalho teve como objetivo verificar a evolução da aprendizagem dos alunos após o uso do software GeoGebra no conceito de área e perímetro de quadriláteros, especificamente retângulos. Porém, abrangeu outros assuntos, além das descobertas das funcionalidades e facilidades que o aplicativo GeoGebra apresenta.

\title{
Metodologia
}

Este trabalho foi desenvolvido após a aplicação da $2^{\mathrm{a}}$ edição da Prova Paraná, em junho de 2019. Verificou-se que alguns descritores específicos apresentaram desempenho muito abaixo do esperado em toda a rede pública de ensino do estado Paraná, dentre eles o descritor D13, que trata da resolução de problemas envolvendo o cálculo de área de figuras planas, e, portanto, foi escolhido como objeto de estudo neste trabalho. Foram selecionadas duas turmas dos anos finais do Ensino Fundamental do Colégio Estadual Bibiana Bitencourt, na cidade de Guarapuava - PR, cujo percentual de acertos na questão envolvendo cálculo de área de figuras planas na $2^{\mathrm{a}}$ edição da Prova Paraná foi muito baixo.

Durante 15 dias todos os professores da rede pública estadual do Estado do Paraná trabalharam com "nivelamento", que se caracterizou por trabalhar os descritores de Língua Portuguesa e Matemática que apresentaram maior índice de erros na $2^{\mathrm{a}}$ edição da Prova Paraná. A atividade foi aplicada em duas turmas do Ensino Fundamental: $8^{\circ}$ e $9^{\circ}$ Anos. As duas turmas tiveram um desempenho muito baixo no descritor que trata do cálculo de área de figuras planas. $\mathrm{O}$ objetivo era de que os alunos compreendessem o conceito de área utilizando o software. A atividade colocou os estudantes em um ambiente de aprendizagem diferente do que estavam acostumados: o laboratório de informática, utilizando um software de geometria, GeoGebra.

Nestes ambientes conceitos geométricos são construídos com equilíbrio conceitual e figural; a habilidade em perceber representações diferentes de uma mesma configuração se desenvolve; controle sobre configurações geométricas levam a descoberta de propriedades novas e interessantes. Quanto as atitudes dos alunos frente ao processo de aprender: experimentam; criam estratégias; fazem conjeturas; argumentam e deduzem propriedades matemáticas. A partir de manipulação concreta, 
VIII Congresso Brasileiro de Informática na Educação (CBIE 2019)

Anais dos Workshops do VIII Congresso Brasileiro de Informática na Educação (WCBIE 2019)

"o desenho em movimento", passam para manipulação abstrata atingindo níveis mentais superiores da dedução e rigor, e desta forma entendem a natureza do raciocínio matemático. [Gravina 1996 p. 13].

No $8^{\circ}$ Ano, 19 alunos fizeram a prova e 02 deles $(11,11 \%)$ acertaram a questão 04 (figura 3).

\section{Questão 04}

D13 - Resolver problema envolvendo o cálculo de área de figuras planas.

04) (M070090G5) Janaína comprou papel decorativo suficiente para cobrir toda a parede que fica atrás da cabeceira da sua cama. Essa parede tem formato retangular e está colorida de cinza no desenho abaixo.

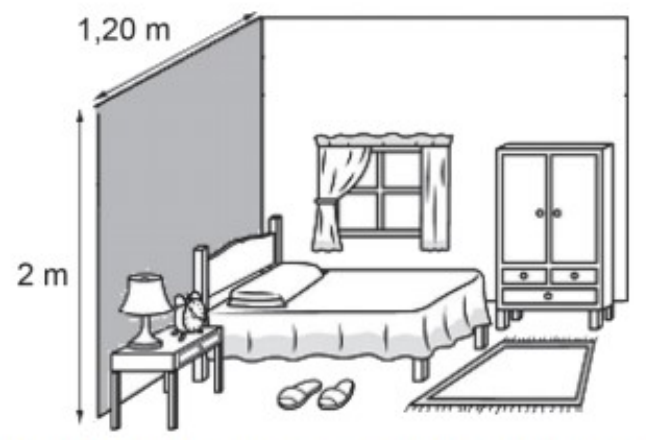

Quantos metros quadrados de papel decorativo, no mínimo, Janaína comprou para cobrir toda essa parede?
A) 2,40
B) 3,20
C) 5,76
D) 6,40

Figura 3. Questão 04 do $8^{\circ}$ Ano do Ensino Fundamental da $2^{\mathrm{a}}$ edição da Prova Paraná

Questão 11

D13 - Resolver problema envolvendo o cálculo de área de figuras planas.

11) (SP082M) Observe, a seguir, a planta baixa da sala do apartamento de Catarina, cujo formato é composto pela justaposição de duas superfícies retangulares.

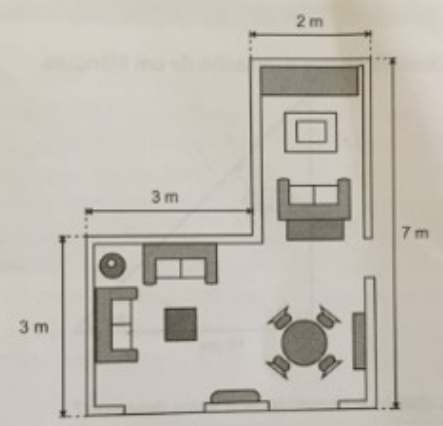

Qual é a área da sala do apartamento de Catarina?

A) $20 \mathrm{~m}^{2}$

B) $23 \mathrm{~m}^{2}$

C) $29 \mathrm{~m}^{2}$

D) $35 \mathrm{~m}^{2}$ 
VIII Congresso Brasileiro de Informática na Educação (CBIE 2019)

Anais dos Workshops do VIII Congresso Brasileiro de Informática na Educação (WCBIE 2019)

Figura 4. Questão 11 do $9^{\circ}$ Ano do Ensino Fundamental da $2^{\mathrm{a}}$ edição da Prova Paraná

O baixo desempenho dos estudantes nas questões relativas ao cálculo de área na Prova Paraná deixou evidente que estes não assimilaram o conceito da forma como lhes foi repassado, isto é, através de exercícios na lousa e caderno.

A atividade foi desenvolvida no laboratório de informática que foi instalado recentemente no colégio. O laboratório possui 32 netbooks, adquiridos através do Programa Escola Conectada. Apesar do colégio ter passado por um longo período sem laboratório de informática os alunos não tiveram dificuldade para familiarizar-se com o software.

As atividades tiveram duração de quatro aulas de 50 minutos cada, sendo duas aulas em cada dia. Posteriormente foi proposto aos alunos para resolverem novamente as questões referentes ao Descritor 13, o que permitiu avaliar a evolução de desempenho após atividades com o software GeoGebra e, assim, verificar a eficiência desta ferramenta tecnológica no processo de aprendizagem em Matemática. Contudo, em nenhum momento durante as atividades foi feito referências as questões da Prova Paraná para não influenciar nos resultados.

\section{Resultados e Discussão}

No primeiro momento os alunos exploraram o software (figura 5). A interface do software apresenta botões que representam as ferramentas a serem escolhidas. Quando um deles é clicado, aparece o nome da opção e como utilizá-la. A cada descoberta eram ouvidas falas como "Olha, dá para fazer uma reta!", "Esse aqui faz um círculo!" e "As coisas se mexem, isso é muito louco!". Estavam descobrindo o que poderiam fazer com o software e de que forma ele poderia ser usado. Apesar de serem séries diferentes as atividades abaixo descritas foram desenvolvidas nas duas turmas, visto que o grau de dificuldade que os alunos apresentam relacionado ao assunto é o mesmo.

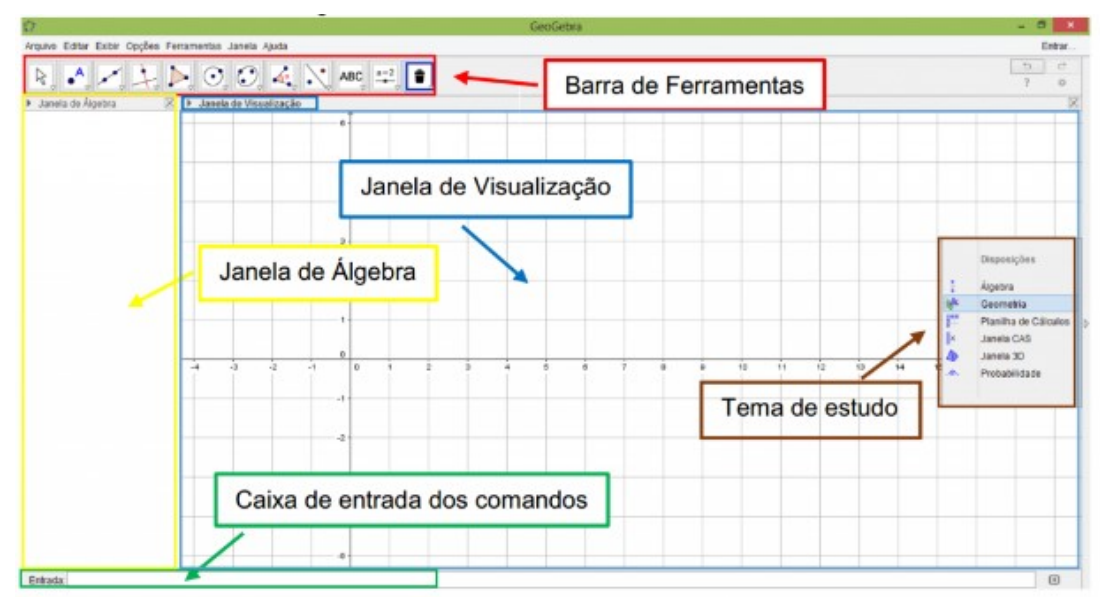

Figura 5. Tela inicial do Geoebra versão 5.0

$\mathrm{Na}$ sequência foi solicitado aos alunos que construíssem um retângulo, sem especificar as dimensões. Alguns alunos descobriram rapidamente como fazer, utilizando principalmente a ferramenta polígono (figura 6). Mesmo os que de início apresentaram alguma dificuldade logo familiarizaram-se com as ferramentas e todos conseguiram cumprir a tarefa. 
VIII Congresso Brasileiro de Informática na Educação (CBIE 2019)

Anais dos Workshops do VIII Congresso Brasileiro de Informática na Educação (WCBIE 2019)

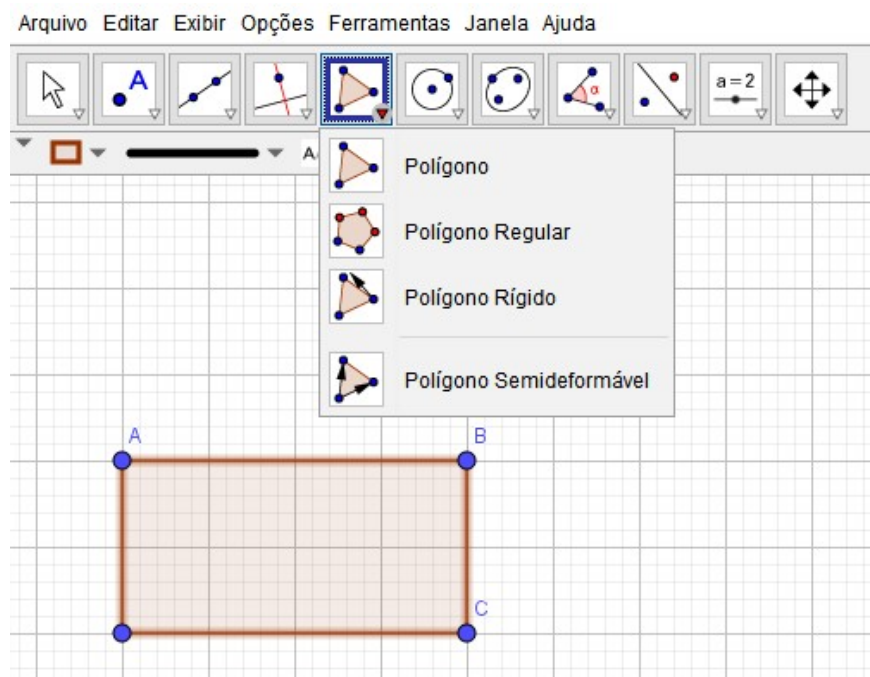

Figura 6. Ferramenta polígono

Após o contato inicial, com os alunos estavam mais seguros para utilizar o software, deu-se início às atividades. Apesar do objetivo principal ser trabalhar com a área de figuras planas, nas atividades foi solicitado o cálculo do perímetro, pois grande parte dos alunos confunde os dois conceitos.

Atividade 1: Construa os quadriláteros abaixo utilizando o $(\quad$ ) como unidade de medida.
a) Quadrilátero 1:3 x 4
b) Quadrilátero 2: 6 x 5
c) Quadrilátero 3: 4 × 4
d) Quadrilátero 4: 2 × 5

A atividade foi desenvolvida com interesse por todos os alunos. Alguns necessitavam apagar e refazer várias vezes, mas realizaram a atividade com muito entusiasmo. Na sequência os alunos foram instruídos a utilizar a ferramenta Distância,

Comprimento ou Perímetro

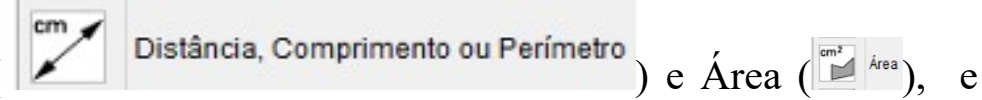
determinar o perímetro e a área e comparar os resultados (figura7). Os alunos registraram no caderno os resultados e justificaram os resultados apresentados pelo software.

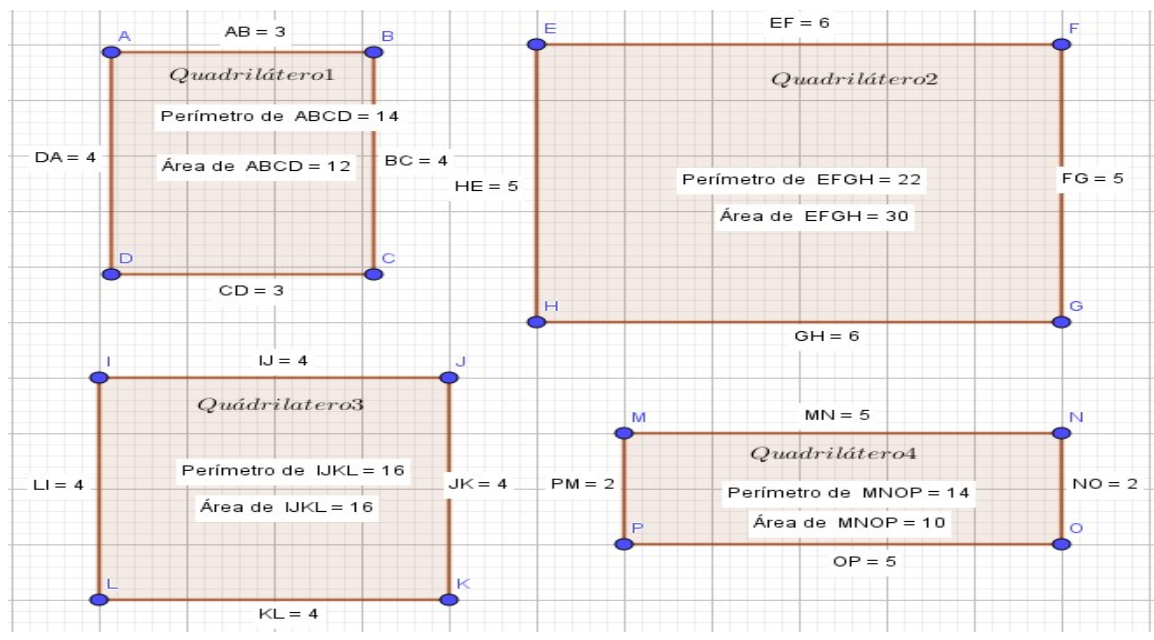


VIII Congresso Brasileiro de Informática na Educação (CBIE 2019)

Anais dos Workshops do VIII Congresso Brasileiro de Informática na Educação (WCBIE 2019)

\section{Figura 7. Cálculo área e perímetro quadriláteros}

Ao realizar os registros no caderno muitos alunos se depararam com a dúvida sobre como calcular a área e perímetro, pois não entendiam como surgiram os resultados apresentados pelo software. Aos poucos foram relacionando as medidas e perceberam nos seus registros que o perímetro era sempre a soma das medidas dos lados e a área era o resultado do produto do comprimento pela largura. Começaram a surgir expressões do tipo: "perímetro sempre soma!"e "putz, agora entendi como calcular a área!"

$\mathrm{Na}$ sequência foi solicitado para os alunos moverem os vértices, mantendo a forma da figura e que observassem o que acontecia com os valores da área e do perímetro e discutissem com o colega ao lado. A geometria dinâmica possibilitou realizar as análises e constatar que as justificativas que tinham feito para o cálculo de área e perímetro eram válidas, gerando assim o aprendizado.

Durante a atividade vieram à tona outros conceitos, como: nomenclatura de pontos e segmentos de reta, definição de reta, segmento de reta e semirreta, medida de ângulos, etc. As dúvidas surgiam na medida que os alunos exploravam o software. Por meio das manipulações do objeto elas puderam ser percebidas e argumentadas. Como articulado por Piaget (1995), citado em Basso e Notare (2012), quanto maior é a ação do sujeito com o meio, maior será sua capacidade de aprender, retirando das coordenações das ações novas coordenações e sintetizando-as em estruturas, como as lógicas e matemáticas. Algo que não ocorreria se a aula fosse na lousa.

A próxima atividade foi construir e calcular área dos polígonos $\mathrm{ABCDEF} \mathrm{E}$ GHIJKLMN (figura 7) e fazer os registros justificando os resultados no caderno.

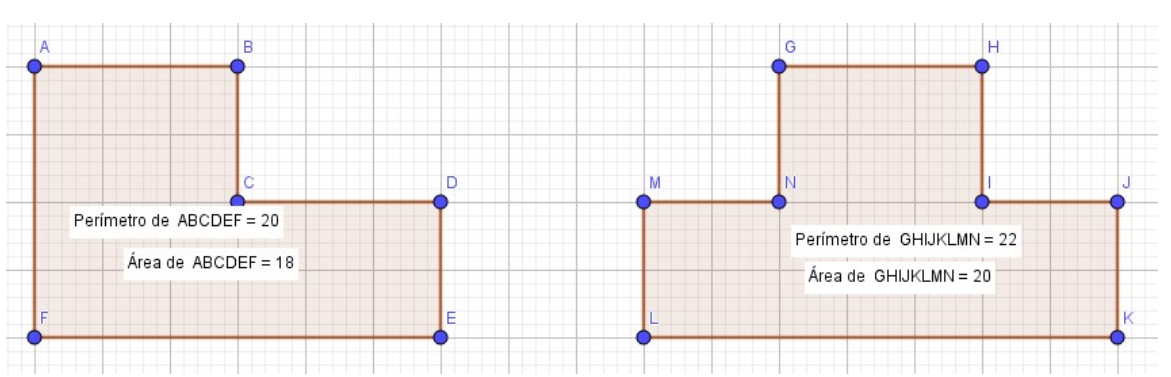

Figura 8. Cálculo área e perímetro polígonos

Os alunos demonstraram habilidade na construção dos polígonos, não sendo mais necessário auxiliá-los e logo realizaram as justificativas no caderno, quando surgiu a dúvida: como calcular área. Mas logo um aluno comentou: "professora acho que eu sei! E se dividir a figura, teremos retângulos e quadrados, aí calcula a área de cada parte e depois soma as partes?" Alguns realizaram os cálculos no caderno e outros dividiram a figura no computador. Surgiram observações de que a figura poderia ser divida de maneiras diferentes, mas o resultado final não se alteraria.

As atividades tiveram duração de quatro aulas de 50 minutos cada, sendo duas aulas em cada dia.

Após o período de nivelamento os alunos do $8^{\circ}$ Ano refizeram na sala de aula a questão 04 e os alunos do $9^{\circ}$ Ano refizeram a questão 11 da Prova Paraná e o resultado 
VIII Congresso Brasileiro de Informática na Educação (CBIE 2019)

Anais dos Workshops do VIII Congresso Brasileiro de Informática na Educação (WCBIE 2019)

das questões que envolviam o cálculo de área teve uma melhora expressiva, conforme tabela 1. Quando questionados sobre o motivo da melhora do desempenho os estudantes apontaram as atividades realizadas no GeoGebra.

Tabela 1. Percentual de acertos da questão Descritor 13

\begin{tabular}{|c|c|c|}
\hline TURMA & $\mathbf{2}^{\mathbf{a}}$ EDIÇÃO PROVA PARANÁ & APÓS NIVELAMENTO COM O GEOGEBRA \\
\hline $8^{\circ} \mathrm{B}$ & $11 \%$ & $79 \%$ \\
\hline $9^{\circ} \mathrm{B}$ & $10 \%$ & $60 \%$ \\
\hline
\end{tabular}

Desta forma, verificou-se que o uso do software GeoGebra é uma ferramenta tecnológica com grande potencial para o ensino da Matemática, sendo um elemento motivador e que contribui no processo de construção do conhecimento matemático.

\section{Conclusão}

Esse artigo teve a intenção de apresentar uma possibilidade de construção de um ambiente de aprendizagem, que propicie o aprendizado de Geometria, por meio da Geometria Dinâmica, em um cenário para investigação. Ou seja, um espaço no qual o aluno pudesse manipular os objetos geométricos, formular questões, procurar explicações, estabelecer relações, observar características.

O conceito de área da forma como vem sendo ensinado na maioria das escolas não está sendo assimilado pelos alunos. As pesquisas, avaliações internas e externas têm mostrado a dificuldade de compreensão dos alunos. Segundo Belleiman Lima (2000, p.2), esse conceito é "dos mais importantes no ensino-aprendizagem da matemática" e relevante "para a formação do cidadão pleno", visto que, em suas atividades cotidianas, tem a necessidade de medir regiões planas como terrenos, pisos, paredes, faces de objetos. Além de sua relevância utilitarista, o conceito de área é rico por interligar os outros eixos da matemática (números, grandezas e álgebra) e por suas aplicações em outras áreas do conhecimento.

As atividades realizadas no software GeoGebra permitiram que o aluno pudesse construir e manipular os objetos geométricos, formular questões, procurar explicações e estabelecer relações, o que seria mais difícil com o desenho estático.

É possível trabalhar com tecnologia nas atividades escolares, mas para isso é necessário que o professor esteja aberto a novas possibilidades de ensino-aprendizagem e que este seja capacitado para fazê-lo, pois, segundo Valente (1999 p.107), implementar computadores nas escolas sem o devido preparo de professores e da comunidade escolar, não trará os benefícios que esperamos.

\section{Referências}

Basso, M. V. A.; Notare, M. R. (2012) “Tecnologia na Educação Matemática: Trilhando o Caminho do Fazer ao Compreender". RENOTE: Revista Novas Tecnologias na Educação, Porto Alegre, v. 10, n. 3, p. 1-11, dez.

Blasis E., Falsarella A. M., Alavarse O. M. (2013) "Avaliação e Aprendizagem: Avaliações externas: perspectivas para a ação pedagógica e a gestão do ensino". 
VIII Congresso Brasileiro de Informática na Educação (CBIE 2019)

Anais dos Workshops do VIII Congresso Brasileiro de Informática na Educação (WCBIE 2019)

Coordenação Eloisa de Blasis, Patricia Mota Guedes. - São Paulo: CENPEC: Fundação Itaú Social, 48p.

Bellemain, P. M. B. E Lima, P.F. (2000) “Análises prévias à concepção de uma engenharia de formação continuada para professores de matemática do ensino fundamental". Anais da 23 reunião anual da ANPED - Caxambu. 2000.

Borba, M. C.; Villarreal, M. E. Humans-with-media and the reorganization of mathematical thinking: information and communication technologies, modeling, experimentation and visualization. New York: Springer, 2005. 229 p.

Dante, L.R. (2018) “Teláris matemática, $8^{\circ}$ ano: ensino fundamental, anos finais". 3 ed, São Paulo: Ática.

Gravina, M. A. (1996) "Geometria Dinâmica: Uma nova abordagem para o aprendizado da Geometria”. Simpósio Brasileiro de Informática na Educação, 7., Belo Horizonte. Anais ...SBIE. p.1-13, nov.

Henrique, M. P. (2017) "GeoGebra no Clique e na Palma das Mãos: Contribuições de uma Dinâmica de Aula para Construção de Conceitos Geométricos com Alunos do Ensino Fundamental". 123f. Dissertação (Mestrado em Educação em Ciências e Matemática) - Universidade Federal Rural do Rio de Janeiro - Instituto de Educação, Seropédica, RJ.

Menezes, B. S. (2018) "Utilização do Geogebra com smartphone: Geometria Dinâmica por meio de um cenário para investigação". Revista REMAT, v.4.n.1, p.68-77, agosto.

Skovsmose, O. (2000) “Cenários para Investigação”. Bolema: Boletim de Educação Matemática. Rio Claro, n. 14, 66-91.

Valente, J. A (1999) (Org.). "O Computador na Sociedade do Conhecimento". Campinas, Sp: Unicamp/Nied. 